\title{
Los momentos líricos de La Araucana
}

H ARTo sabemos todos lo que es La Araucana y lo que su condición 11 de poema épico-heroico significa en la historia de las letras hispánicas. Aun la crítica menos dada al elogio ha reconocido en ella un valor sin igual entre todos aquellos' escritos que en verso - sin mencionar ahora las crónicas de la época- relatan con mayor o menor fortuna los hechos de la Conquista, que sus autores trataron, en la mayoría de las veces, para dar una fe de vida y de acción en los mismos. El propio Juan de Castellanos, en su dedicatoria de las Elegias a Felipe II dice que las escribió por "consejo y estímulos de amigos que se dolían de ver hazañas esclarecidas quedarse para siempre sepultadas / en las escuridades del olvido... (Y observe el que me escucha que, sin quererlo, estas dos últimas frases le han salido en dos endecasilabos perfectos). Repito: "quedarse para siempre sepultadas / en las escuridades del olvido". Y el mismo casi siempre prosaico Castellanos, al comienzo de la Tercera parte de las Elegías dedica un soneto "Al lector" que termina con sus dos dignísimos tercetos:

La peregrinación es inexausta, la vida breve, vena mal propicia para me detener en las jornadas.

$Y$ ansí vamos de paso porque Dasta en aqueste compendio dar noticia de las cosas que estaban olvidadas.

La intención es en casi todos estos escritores la misma: recordar el pasado próximo o remoto. Y' al hacerlo así, presentar a España una galería de retratos o paisajes, de acciones guerreras y hechos heroicos que sirviera como justificación de sus aventuras; o, mejor dicho, de la gran aventura de la Conquista. 
No se aparta Ercilla del conjunto de sus contemporáneos. La historia es en su poema lo que más importa; máxime cuando esa historia que versifica la ha presenciado él casi toda, tomando en ella parte principal y siendo por lo tanto personaje vivo en sus páginas. Tampoco se diferencia en lo que a forma respecta: la octava real, que nos llegó a las letras castellanas en el poema de Boscán y que pasó bien pronto a nuestra épica y en ella tomó carta de naturaleza, aun con la variante con que la dispuso Pedro de Oña. Interminables octavas que si pudiéramos arreglarlas en una línea continuada tal vez serían bastantes para atravesar el Atlántico de una a otra orilla.

Toda la literatura escrita acerca de La Araucana - que con El Arauco domado de Oña llena una época-se fija más bien en los hechos, elogia la poderosa manera con que Ercilla nos va llevando a través de su historia por' entre grupos de españoles y araucanos y ensalza a Caupolicán, a Lautaro, a las heroicas doña Mencía de Nidos, a Guacolda, a Glaura, a Fresia y a Tegualda. Don Marcelino Menéndez y Pelayo afirma categóricamente:

No hay en La Arducana ni una Inés de Castro, ni un Magricio, ni un Adamástor, ni una isla de los Amores, que vengan a recrear la fantasía con más apacibles paisajes o más dulces afectos. Las sombras de Tegualda, de Glaura, de Guacolda, pasan rapidísimas, y siempre mezcladas al fragor del combate y envueltas en el cálido vapor de la sangre.

Claro es que así tenía que ser. Inés de Castro bien se estuvo en su corte de Portugal; y Magricio con los Doce Pares, y Adamástor asustando con su gigantesca figura a Vasco de Gama. Y para encontrar otra isla de los Amores hemos de llegar hasta Pedro de Oña, que nos brinda una de las escenas más tiernamente lascivas que encontramos en la poesía de su época. Pero si en Ercilla no hay Inés de Castro, hay en cambio esas breves pero dramáticas figuras de doña Mencía de Nidos y la triste sombra dolorosa de Tegualda buscando entre la noche el cadáver de su esposo-episodio justamente elogiado por todos, gracias al misterio en que su autor lo envuelve y a la gravedad del momento en que sucede.

No hay que olvidar, tampoco, aquella serie de octavas en que se nos presenta a la vista, con singular fuerza y rapidez vertiginosa, el incendio y saqueo de la ciudad de Concepción descritos en el Canto VII de la Primera Parte, ni la elección de Caupolicán para dirigir, como "toqui", la revuelta de su pueblo contra los españoles, en la que el paso 
del tiempo y la acción del personaje corren parejas en un ejemplar alarde de técnica poética.

Mas sin detenernos por mayor espacio en estos y otros momentos memorables de La Araucana, quiero llegar al tema de estas notas, que no es otro que señalar aquellos versos en los que Ercilla se muestra verdadero poeta lírico - seguidor de la vena de Garcilaso, por ejemplo. Angel del Río en su Historia de la literatura española dice estas palabras: "La Araucana ha sobrevivido al desvío actual hacia los poemas de su tipo por la relativa abundancia de pasajes de bella poesía..." Concha de Salamanca [Concha Zardoya] comenta: "algunas veces hallamos en ella [en La Araucana] versos de fino lirismo, de auténtica poesía o de perfección formal". Atturo Souto, en la introducción a la edición del poema de 1962, encuentra "a veces remansos de intenso, profundo lirismo". Y Anderson Imbert en su Historia: "Ercilla solía escaparse con escenas de amor, profecías, apariciones sobrenaturales, sueños líricos, mitologías embellecedoras, viajes imaginarios..."

Vamos, pues, a ver juntos esos momentos. $Y$ a relacionarlos con su vocación primera, torcida, desviada en 1554, cuando contaba 21 años, por la otra de la aventura y la guerra. Él mismo va a decir, como lamentándose de su presente estado, en la octava cuarta del Canto XX:

¿Quién me metió entre abrojos y por cuestas, tras las roncas trompetas y atambores, pudiendo ir por jardines y florestas cogiendo varias y olorosas flores, mezclando, en las empresas y recuestas, cuentos, ficciones, fábulas y amores, donde correr sin limite pudiera, $y$, dando gusto, yo le recibiera?

Hay, a mi modo de, ver, dos pequeños subtemas, a los que se alude en la octava que acabamos de ver: el amor y el campo. No ya el amor cuando aparece entre los araucanos, ni el campo seudo americano en el que sus personajes se mueven, sino los que le han llegado a Ercilla por caminos diversos: el paisaje renacentista de las églogas de Garcilaso con sus olmos y yedras, ríos tranquilos que pasan su corriente al lado de las florecillas silvestres, y sobre todo ello, con aquella "capacidad de recuerdo" que menciona Concha Zardoya en su edición del poema: el amor.

Pero vayamos por partes. En primer lugar, ¿cómo es ese campo de Ercilla en las escenas más apacibles de su obra? Cuando en el Canto I 
de la Parte I va a dar noticia del concilio que para hacer la guerra a los españoles se disponen a tener los araucanos, nos lo describe así:

Hácese este concilio en un gracioso asiento en mil florestas escogido, donde se muestra el campo más hermoso de infinidad de flores guarnecido; alli, de un viento fresco y amoroso los árboles se mueven con ruido, cruzando muchas veces por el prado un claro arroyo limpio y sosegado.

Do una fresca y altísima alameda por orden y artificio tienen puesta en torno de la plaza, y ancha rueda, capaz de cualquier junta y grande fiesta, que convida al descanso y al sol veda la entrada y paso en la enojosa siesta; allí se oye la dulce melodía del canto de las aves y armonía.

Y más adelante, en el Canto XVII de la Segunda Parte, al aparecérsele Belona en sueños para hacerle ver la batalla de San Quintín, le dice que va a llevar al poeta, y a situarlo:

En campo fértil, lleno de mil flores, en el cual hallarás materia llena de guerras más famosas y mayores donde podrás alimentar la vena; y si quieres de damas y de amores en verso celebrar la dulce pena, tendrás mayor sujeto y hermosura que en la pasada edad, y en la futura.

Alli, en ese campo, hay claras fuentes que murmuran, y templados. vientos respirando, y verde hierba, y pájaros y árboles otra vez. $\mathrm{Y}$ para que sea un paisaje con figuras, coloca en él ninfas que cogen flores y cantan dulces letras amorosas, y hay además sátiros, faunos y silvanos. ¿Ah!, conque aquél que al comienzo de su poema se proponía cantar "no las damas, amor, no gentilezas" de caballeros enamorados, "sino el 
estruendo y armas de la guerra", necesita de vez en cuando de un refugio a su bélico quehacer, y distraerse, aunque en sueños, en otros lugares y entre otras figuras que las de los fieros hombres del Arauco. Y es que su vocación le llevaba a recrearse entre las damas de su España, que en otras octavas de ese mismo Canto XVII aparecen con sus galanes "al regalado y blando amor rendidos, / unọ en esperanza sostenidos; / otros, en sus riquezas confiados; / todos gozando alegres y contentos / de sus lozanos y altos pensamientos". Ya volveremos a esta escena, en la que hemos de ver enlazarse, de modo realmente encantador, ese paisaje de novela pastoril, de égloga galante, con el otro tema a que antes me referí: el del amor. Fijémonos, por el momento, en la gracia y elegancia de los endecasílabos de Ercilla. Aquí, a lo que me parece, le sale la palabra como al ritmo de una danza campestre y al son de liras y flautas. "Al regalado y blando amor rendidos". Con la aliteración de dulce, lindo, delicado, y dolor y deseo. La "de" de los divinos deliquios ardorosos. ¿No parece que estamos en otro mundo diferente del de sus pasos por Chile? Parece, sí. Mas advirtamos desde luego que el paisaje es el mismo que el otro. Ercilla, como muchos de sus contemporáneos, pinta un paisaje que sólo es trasunto del europeo eglógico. Lo que sucede es que en el dulce campo araucano que asoma a veces en sus octavas iniciales no pueden aparecer esas "damas, amor, y gentilezas". Por ello, y llevado de su natural vocación de poeta galante, de cortesano, de renacentista, aprovecha la ocasión que Belona le of rece para dar a su verso un tempo más despacioso, y recrearse en la visión de esta escena, que tal vez no sea sino un recordar, en su viaje de ida y vuelta a través del océano, aquellas fiestas galantes en las que debió de participar en su más florida juventud. Advirtamos también, de paso, que en la quinta octava del Canto XV de la Primera Parte va a confesarnos que

pues como otros han hecho, yo pudiera entretejer mil fábulas y amores;

y a continuación:

mas ya que tan adentro estoy metido, habré de proseguir lo prometido.

Es curioso notar - ya se ha notado- que al final del Canto XV ha dejado Ercilla a dos guerreros, el fiero Andrea y el ensangrentado Rengo, que quedan "las inhumanas armas levantando"; y asi los mantiene, in- 
móviles como en una vista fija, suspendiendo su verso hasta el Canto siguiente. Recurso que iba a emplear más tarde Cervantes al final del Capítulo VIII de la Primera Parte del Quijote, en el encuentro entre el Caballero y el vizcaíno. Comienza el Capítulo IX: "Dejamos en la primera parte de esta historia al valeroso vizcaíno y al famoso don Quijote con las espadas altas y desnudas, en guisa de descargar dos furibundos fendientes", etc. Ercilla, en la octava sexta del Canto XV de la Primera Parte escribe de modo semejante:

Al lombardo dejé y al araucano donde la guerra andaba más trabada, la espada alta y la maza levantada...

Mas lo que ocurre en el poeta que nos ocupa es que antes de reanudar la historia de esa feroz batalla inicia el Canto con un intermedio lírico como para alivar la tensión del lector y, al mismo tiempo, desahogarse en un suspiro, en aquel verso clave de la tercera octava: "Pues yo de amor desnudo y de ornamento".

De amor desnudo. Ya nos ha contado don José Toribio Medina, el autor de esa Vida de Ercilla imprescindible, cómo, además del deseo de aventura, iba en Ercilla la viva herida de un amor contrariado, de una pasión que le acompañaría muchos años y que él dejaba escapar de su alma en versos teñidos de melancolía que aparecen como tristes flores entre los más fuertes rugidos de la guerra. Aun antes de salir de España, es decir, cuando apenas contaba veinte años, había compuesto don Alonso una "glosa", su primer paso en el camino de la poesía, que fue bien conocida entonces, tanto, que Lope - y cito palabras de Medina- "al bosquejear en su Laurel de Apolo (es en la Silva IV), la figura de Ercilla como poeta y como hombre, aludía a ese su amor contrariado de su juventud, señalándolo como uno de los rasgos más característicos de su vida". En efecto, Lope nos habla del ingenio del poeta que desde Chile viene

a enriquecer la musa de Castilla.

Porque después del grave Garcilaso

fue Colón de las Indias del Parnaso

y más cuando en el único instrumento

cantaba en tiernos versos lastimado:

"que ya mis desventuras han hallado

el término que tiene el sufrimiento". 
Ercilla había escrito en aquella "glosa" verdaderos versos de amor, tiernas querellas. $\mathrm{Y}$ en una estrofa, la segunda, se pregunta:

¿Qué desventura habrá para mí nueva?

¿Qué pena es la que yo no he padecido?...

Esas preguntas hallan eco, precisamente, en la primera octava del Canto XXII:

¿Pérfido amor tirano, qué provecho piensas sacar de mi désasosiego?

¿No estás de mi promesa satisfecho que quieres afligirme desde luego? ¡Ay! que ya siento en mi cuidoso pecho labrarme poco a poco un vivo fuego y desde allí con movimiento blando ir por venas y huesos penetrando.

¿No ves que es mengua tuya y gran bajeza habiendo tantos célebres varones, venir a mendigar a mi pobreza, tan falta de conceptos y razones, y en medio de las armas y aspereza, sumido en mil forzosas ocasiones, me cargas por un sueño quizá vano con tanta pesadumbre ya la mano?

Y le increpa y le dice: "Déjame ya". ¿Por qué? Porque está metido en el negocio de la guerra y debe "cumplir lo prometido / aunque tire a otra parte mi deseo". Vuelta, pues, al dilema. Por una parte, el empeño que se ha impuesto de narrar los sucesos de la guerra. Y por la otra, socavadamente, un ansia de amor, de amar, de cantar al amor y a la mujer le inquieta y desasosiega.

Tanto puede en Ercilla ese deseo de cantar al amor, que - volviendo ahora nosotros al momento de la espada y la maza levantadas en que nos dejó al final del Canto XIV-, va ahora no a quejarse del dios, sino a ensalzarlo, preludiando en estas dos estrofas - anunciando, mejor dicho-, su caída a los pies de doña María de Bazán, que fue su esposa, según veremos al comentar el Canto XVIII de la Segunda Parte. Ahora 
va a decir, con ánimo exaltado y elocuente palabra, las glorias del amor, como antes nos pintó sus pesares:

¿Qué cosa puede haber sin amor buena?

¿Qué verso sin amor dará contento?

¿Dónde jamás se ha visto rica vena

que no tenga de amor el nacimiento?

No se puede llamar materia llena

la que de amor no tiene fundamento;

los contentos, los gustos, los cuidados,

son, si no son de amor, como pintados.

Amor de un juicio rústico y grosero

rompe la dura y áspera corteza,

produce ingenio y gusto verdadero

y pone cualquier cosa en más fineza;

Dante, Ariosto, Petrarca y el Ibero, amor los trajo a tanta delgadeza, que la lengua más rica y más copiosa, si no trata de amor es disgustosa.

Ya dije que este canto al amor me parece como el preludio de 10 que Ercilla va a desarrollar más tarde en el poema: la aparición, en sueños, en aquel sueño fantástico por el que lo lleva Belona a presenciar la batalla de San Quintín y a predecir otros sucesos de la historia de Europa. Por fin, en aquel campo florido al que me referí al comienzo de estas cuartillas, donde se hallaba "gran copia de galanes estimados / al regalado y blando amor rendidos", se encuentra nuestro poeta (en el Canto XVIII) que ha sido arrebatado por el aire vano. Y:

Que luego que los pies puse en el suelo los codiciosos ojos ya cebando, libres del torpe y del grosero velo que la vista hasta allí me iba ocupando, un amoroso fuego y blando hielo se me fue por las venas regalando, y al brío rebelde y pecho endurecido quedó al amor sujeto y sometido

Otra vez el amor. Ya ni queja, ni alabanza incierta. Sometimiento a una 
realidad que ha de acompañarle ya para siempre. Una mujer. Recordemos el verso de Espronceda:

Una mujer. Deslízase en el cielo allá en la noche desprendida estrella...

¿Lo recordais? Una mujer. $Y$ ésta ya tiene nombre. Pasó el momento del amor contrariado. Ya va a tener nombre. $Y$ va a ser doña María de Bazán. Escuchemos al poeta:

$\mathrm{Y}$, deseoso luego de ocuparme en obras y canciones amorosas, y mudar el estilo y no curarme de las ásperas guerras sanguinosas, con gran gana y codicia de informarme de aquel asiento y damas tan hermosas, en especial y sobre todas una, que vi a sus pies rendida mi fortuna.

Era de tierna edad, pero mostraba en su sosiego discreción madura, y a mirarme parece la inclinaba su estrella, su destino y mi ventura...

(Ved qué excelente endecasilabo, que se adelanta en tres siglos a algunos de los mejores que Espronceda escribiera.) Pero continuemos:
yo, que saber su nombre deseaba, rendido y entregado a su hermosura, vi a sus pies una letra que decía: del tronco de Bazán doña María.

A sus pies una letra. Como aquellas letras que pintaba Goya a los pies de la Duquesa de Alba, ¿no es cierto?

Ahora, su embeleso queda roto, una vez más, por el estruendo de las armas que, durante las tres octavas finales de este Canto lo vuelven a la realidad del Arauco indomado. Y comienza el siguiente, el XIX, excusándose el poeta con las damas de no poder "esparcir vuestros loores", porque... Mas no. He de leer, como cita final de las muchas que he puesto en estas notas - y que aun pudiera continuar poniendo-, he de 
leer toda la estrofa, para que en ella oigáis, en su cuarto verso, otro momento feliz cual ninguno del Etcilla lírico, creo yo. Escuchad:

Hermosas damas, si mi débil canto no comienza a esparcir vuestros loores y si mis bajos versos no levanto a conceptos de amor y obras de amores, mi prisa es grande y que decir hay tanto, que a mil desocupados escritores, que en ello trabajasen noche y día, para todos materia y campo habría.

$Y$, aunque apartado a mi pesar me veo de esta materia y presupuesto nuevo...

tiene que seguir en su empresa, y dejar galanteos y donaires y ese hermosísimo verso de "conceptos de amor y obras de amores", para otra vez cantar cosas de guerra.

Se me ocurre pensar en' el momento en que escribo estas líneas, qué poeta lírico, de la vena de Garcilaso, de Cetina, de Aldana, hubiese ganado España si don Alonso de Ercilla no hubiese partido a Chile y a su regreso a la península no quedara comprometido consigo mismo a continuar su poema. Por las muestras que en él aparecen esparcidas, por las que hemos visto juntos y las muchas más que no he mencionado, podríamos asegurarle un puesto distinguidísimo en el laurel de Polimnia. Pero su fortuna, el desamor, su deseo de aventura le llevaron muy lejos. $\mathrm{Y}$ de todo ello nos ha quedado La Araucana. Un amor desgraciado puede llevar al suicidio o a la santidad. Muchas veces - las más, creo yo-, puede llevar a la poesía.

EUGENIO FLORIT

Barnard College

Columbia Univerșity 